\title{
openheart Is there a role for a local inpatient CT coronary angiography service in selected patients with acute coronary syndrome? A cohort analysis of inpatient tertiary centre referrals for invasive coronary angiography
}

Hamish MacLachlan, Ranji Thomas, Jessica Langtree, Chris Hare, Andrew R J Mitchell

To cite: MacLachlan $\mathrm{H}$, Thomas $\mathrm{R}$, Langtree $\mathrm{J}$, et al. Is there a role for a local inpatient CT coronary angiography service in selected patients with acute coronary syndrome? A cohort analysis of inpatient tertiary centre referrals for invasive coronary angiography. Open Heart 2016;3:e000389. doi:10.1136/openhrt-2015000389

Received 22 December 2015 Revised 25 January 2016 Accepted 26 January 2016

CrossMark

Department of Cardiology, Jersey General Hospital, Jersey, UK

Correspondence to Dr Andrew R J Mitchell; an.mitchell@health.gov.je

\section{ABSTRACT}

Objective: To conduct a retrospective analysis of inpatients referred for invasive coronary angiography (ICA) at a tertiary centre, with suspected or confirmed acute coronary syndrome (ACS).

Methods: A retrospective cohort study was conducted at Jersey General Hospital. We evaluated 198 inpatients referred for ICA with suspected or confirmed ACS over a 3-year period. Patients presenting with ST elevation myocardial infarction were excluded. The primary outcome was to identify the number of patients who did not require subsequent coronary intervention following ICA. Patient variables were measured to establish those who met European Society of Cardiology (ESC) criteria for consideration of CT coronary angiography (CTCA) as an alternative to ICA. Cost of care for those referred for ICA was calculated. Results: ICA demonstrated evidence of coronary heart disease requiring coronary intervention in $119(60 \%)$ of the referred patients. $28(35 \%)$ of the patients not requiring coronary intervention at ICA met ESC criteria for preassessment with CTCA. The cost of care for this subgroup was £9089 per patient. Inpatient CTCA was calculated at $£ 376$ per patient.

Conclusions: Low-intermediate risk patients presenting with suspected or confirmed ACS to hospitals without onsite coronary revascularisation should be considered for in-hospital CTCA before consideration of ICA. Using CTCA as a gatekeeper for targeted ICA appears cost-effective, particularly for hospitals without the required onsite facilities.

\section{INTRODUCTION}

Approximately 350000 patients present acutely with chest pain to emergency departments (ED) in the UK each year. These patients are assessed for suspected acute coronary syndrome (ACS) using assays of serial biomarkers and 12-lead ECGs. ${ }^{2}{ }^{2}$ If the tests

\section{KEY QUESTIONS}

What is already known about this subject?

- Growing data indicates that cardiac CT coronary angiography (CTCA) cannot only exclude significant coronary heart disease but also delineate anatomy to aid decision-making in the setting of acute coronary syndrome (ACS).

What does this study add?

- Patients with suspected or confirmed ACS with low to intermediate in-hospital mortality risk should be assessed with inpatient CTCA before being considered for interhospital transfer and targeted invasive coronary angiography (ICA).

How might this impact on clinical practice?

- A decision model using CTCA as a gatekeeper for targeted ICA would result in reduced frequency and length of admissions, reduced cost, improved patient experience, and early initiation of preventative therapy. Consideration should be made to other patient groups with suspected or proven ACS.

prove normal, patients are often discharged with a diagnosis of 'troponin negative' chest pain. Further assessment for possible coronary heart disease is inconsistent and is largely dependent on the individual clinician. A quick, safe, accurate and cost-efficient diagnostic tool for patients with suspected ACS is desirable.

Invasive coronary angiography (ICA) remains the gold standard for identifying clinically significant coronary heart disease (CHD). The invasive nature of ICA, however, is associated with a risk of complications (eg, vascular injury, myocardial infarction), cost, radiation exposure and compromise in 
patient experience. Furthermore, referrals for ICA often require inpatient transfer of patients to a regional centre, as only around 35\% of UK hospitals have onsite coronary revascularisation facilities. ${ }^{3}$ This study was undertaken in Jersey General Hospital, in the Channel Islands, where there is no onsite coronary angiography service. Aeromedical transfer of patients referred for ICA is, furthermore, associated with clinical risk and expense.

In cases where ACS is suspected despite non-diagnostic ECG and troponin findings, the European Society of Cardiology (ESC) currently recommends functional testing to ascertain inducible ischaemia, and further guide decisions on invasive strategies. ${ }^{4}$ Furthermore, those with a predetermined low-intermediate risk of CHD should be considered for CTCA as an alternative to ICA. ${ }^{4}$ Despite these recommendations, uncertainty continues as to which non-invasive imaging modality should be used as first-line for the triage of patients with suspected ACS and low-intermediate risk of CHD.

Diagnostic non-invasive imaging techniques can be categorised as anatomical (CTCA) or functional (stress-echocardiography, nuclear medicine and stress MRI). Before evaluating the role of these individually, it would be prudent to add that in real practice, choice of investigation is greatly determined by interhospital variability in available resource and clinician expertise. In terms of functional assessment, stress echocardiography is preferred to exercise testing due to its superior diagnostic accuracy ${ }^{5}$ and prognostic outcomes. ${ }^{6}{ }^{7}$ Advantages of stress echocardiography include availability, low cost and its radiation-free nature. The advantage of cardiac MRI (CMR) is its ability to assess both perfusion and regional wall changes. Favourable short-term and mid-term prognostic outcomes are reported in patients with suspected ACS and normal CMR findings. ${ }^{8}$ Its role in the acute setting of coronary assessment is of course limited by cost and resource. In patients with equivocal ECG changes and cardiac enzymes, combined stress-rest myocardial scintigraphy has been shown to enhance the assessment of ischaemia, and is again associated with favourable outcome. ${ }^{9} 10$

CTCA provides a reliable non-invasive alternative to ICA. ${ }^{11}$ Clinical studies have demonstrated that CTCA facilitates non-invasive risk stratification of CHD with a negative test indicating a favourable prognosis. ${ }^{12} 13$ A systematic review of 21 trials evaluating the diagnostic accuracy of CTCA reported a pooled specificity and sensitivity of $89 \%$ and $99 \%$, respectively, when used to investigate clinically significant CHD. ${ }^{14}$ Heavily calcified coronary arteries on CTCA results in blooming artefact and overestimation of coronary lesions. ${ }^{15}$ Dual energy CT imaging has the potential to attenuate the radiological effects of beam hardening and blooming artefact when imaging heavily calcified vessels. ${ }^{16}$ Iyengar et $a l^{17}$ examined the diagnostic accuracy of high-definition CTCA (HD-CTA) compared with ICA. HD-CTA addresses the shortcomings of CTCA by improving spatial resolution and reducing blooming artefact from coronary calcification without exposing patients to higher doses of radiation. From their interim results, they concluded that HD-CTA has excellent accuracy compared to ICA in patients with high pretest probability of, or established, CHD. Furthermore, its incorporation in an acute chest pain service is feasible and provides early triaging of patients with suspected ACS who present with non-diagnostic troponin and ECG findings. ${ }^{17}$

Accordingly, CTCA could serve as a gatekeeper for ICA in selected patients presenting with suspected ACS, with particular benefit for those hospitals without onsite coronary revascularisation facilities. The objective of this study was to conduct a retrospective analysis of inpatients with suspected or confirmed ACS who were referred for ICA at a tertiary centre. The primary outcome measure was evidence of CHD at ICA requiring percutaneous or surgical coronary intervention. This cohort analysis enabled us to identify the number of patients who met the ESC-recommend criteria for consideration of CTCA as a primary investigation for suspected ACS. The secondary aim was to calculate the total cost of inpatient referral for this subgroup, and evaluate the role of local inpatient CTCA as a cost-effective alternative investigation to tertiary ICA in the context of suspected or confirmed ACS.

\section{METHODS}

A retrospective cohort study was conducted at Jersey General Hospital. Inpatients referred for ICA with suspected or confirmed ACS over a 3-year period (January 2011 to December 2013) were included. Exclusion criteria included ST-segment elevation myocardial infarction (STEMI), or having previously undergone ICA/ CTCA within 2 years (if this investigation revealed obstructive CHD), or 5 years if normal. Patients were categorised into two groups according to the outcome of their ICA: evidence of CHD at ICA requiring revascularisation (intervention group), or no evidence of CHD at ICA requiring revascularisation (non-intervention group). Medical notes were analysed to assess the following patient characteristics: age, sex, number of risk factors for CHD (smoking history, hypercholesterolaemia, diabetes mellitus, peripheral vascular disease), ECG evidence of atrial fibrillation on presentation, ECG evidence of ST-segment depression on presentation, raised high-sensitivity troponin I level (>120 ng/L) prior to transfer, raised serum creatinine level on presentation (male $>101 \mu \mathrm{mol} / \mathrm{L}$, female $>92 \mu \mathrm{mol} / \mathrm{L}$ ), referring diagnosis and out-of-hospital cardiac arrest. Finally, each patient's in-hospital mortality and 6-month mortality risk were calculated using the Global Registry of Acute Coronary Events score. Local departmental finance reports were used to calculate the cost of hospital admission both locally and at the accepting tertiary centre, cost of patient transfer and the cost of ICA at the tertiary 
centre. We calculated a cost of $£ 376$ for inpatient CTCA using current tariff rates of a north-west London NHS hospital trust. Cost data were calculated for the nonintervention group only.

\section{Statistical analysis}

A Student $t$ test was used to compare continuous variable data with values expressed as mean $\mathrm{SD} \pm \mathrm{SD}$. A $\chi^{2}$ or Fishers exact test was used to compare categorical variable data with values expressed as number (\%). Independent predictors of coronary intervention at ICA were assessed using a multivariable Poisson regression model. Two-tailed tests of significance used $\alpha$-level of 0.05 Analyses were performed using STATA software, V.14.

\section{RESULTS}

\section{Study population}

A total of 278 patients with suspected or confirmed ACS were referred for diagnostic ICA between 2011 and 2013. On clinical grounds, ICA was not undertaken in nine

\begin{tabular}{|c|c|c|c|}
\hline $\begin{array}{l}\text { Patient } \\
\text { variable }\end{array}$ & $\begin{array}{l}\text { Non-intervention } \\
(n=79)\end{array}$ & $\begin{array}{l}\text { Intervention } \\
(n=119)\end{array}$ & p Value \\
\hline Age & $62.5(13.7)$ & $63.7(12.0)$ & 0.523 \\
\hline Male & $42(53.2)$ & $95(79.8)$ & $<0.001$ \\
\hline \multicolumn{4}{|l|}{ Risk factors } \\
\hline 0 & $17(21.5)$ & $10(8.4)$ & 0.038 \\
\hline 1 & 16 (20.3) & 37 (31.1) & \\
\hline 2 & 26 (32.9) & $37(31.1)$ & \\
\hline 3 & 17 (21.5) & $24(20.2)$ & \\
\hline$>4$ & $3(3.8)$ & $11(9.2)$ & \\
\hline Heart rate & $82.0(18.5)$ & $86.0(21.5)$ & 0.180 \\
\hline $\begin{array}{l}\text { Systolic } \\
\text { blood }\end{array}$ & $139.4(31.6)$ & $137.9(32.2)$ & 0.746 \\
\hline $\begin{array}{l}\text { pressure } \\
\text { In-hospital } \\
\text { mortality } \\
\text { risk }^{*}\end{array}$ & 96.7 (33.1) & $118.5(28.1)$ & $<0.001$ \\
\hline $\begin{array}{l}\text { 6-month } \\
\text { mortality } \\
\text { risk }^{*}\end{array}$ & $6.1(6.5)$ & $10.4(9.7)$ & $<0.001$ \\
\hline NSTEMI & $52(65.8)$ & $107(89.9)$ & $<0.001$ \\
\hline $\begin{array}{l}\text { Atrial } \\
\text { fibrillation }\end{array}$ & $8(10.1)$ & $11(9.2)$ & 0.836 \\
\hline $\begin{array}{l}\text { ST- } \\
\text { depression }\end{array}$ & $6(7.6)$ & $56(47.1)$ & $<0.001$ \\
\hline $\begin{array}{l}\text { Raised } \\
\text { creatinine }\end{array}$ & $14(17.7)$ & 37 (31.09) & 0.035 \\
\hline $\begin{array}{l}\text { Troponin } \\
\text { rise }\end{array}$ & $49(62.0)$ & 107 (89.9) & $<0.001$ \\
\hline $\begin{array}{l}\text { Cardiac } \\
\text { arrest }\end{array}$ & $5(6.3)$ & $1(0.8)$ & 0.038 \\
\hline \multicolumn{4}{|c|}{$\begin{array}{l}\text { *GRACE In-Hospital Mortality Risk scores: 1-108=low, 109- } \\
\text { 140=intermediate, 141-372=high. GRACE 6-month Mortality Risk } \\
\text { scores: } 1-88=\text { low, 89-118=intermediate, 119-263=high. } \\
\text { GRACE, Global Registry of Acute Coronary Events; NSTEMI, } \\
\text { non-ST-segment elevation myocardial infarction (retrospectively } \\
\text { assessed). }\end{array}$} \\
\hline
\end{tabular}

patients once assessed by the accepting team. A further 61 were excluded with a diagnosis of STEMI and 10 having previously undergone ICA or CTCA within 5 years of presentation. This left 198 patients for analysis. Patient variables of the two groups defined by outcome of ICA (coronary intervention and non-intervention), are summarised in tables 1 and 2. ICA demonstrated evidence of CHD requiring coronary intervention in $119(60 \%)$ of the patients referred over the 3 years; 79 patients $(40 \%)$ were managed medically. Of these, $64(81 \%)$ required no further investigation following ICA, and were discharged with local follow-up. Of the 198 patients referred for ICA, 32 (16\%) were retrospectively deemed low-intermediate risk and presented with inconclusive ECG and troponin findings; 28 $(88 \%)$ of these did not require coronary intervention following ICA. There were statistically significant differences in patient variables between the two groups for: sex, referring diagnosis, number of risk factors for $\mathrm{CHD}$, ST-segment depression, elevated serum creatinine, elevated troponin, out-of-hospital cardiac arrest, in-hospital mortality risk and 6-month mortality risk. All patient variables in the multivariable model were each significantly associated with coronary intervention in the univariate model. However only sex, ST-segment depression, and risk factors of 1 or $>4$, were independently associated with coronary intervention at ICA. The mean calculated in-hospital mortality risks of the non-intervention and intervention groups were $0.9 \%$ (low) and $4.4 \%$ (intermediate), respectively. The mean 6-month calculated mortality risks of the nonintervention and intervention groups were $2.1 \%$ (intermediate) and $8.1 \%$ (high), respectively. The calculated risk distribution of the two groups is illustrated in figure 1 .

\section{Patient cost}

Cost of inpatient referrals for the 79 patients not requiring coronary intervention is itemised in table 3 . The overall referral cost was $£ 728950$ or $£ 9227$ per patient. From the time of peak troponin I level, the nonintervention group remained inpatients for a mean 4 days prior to transfer, costing $£ 116022$. The same subgroup required a mean 4-day admission at the tertiary centre before discharge home, costing $£ 37584$. This figure does not include downstream costs for those remaining inpatients after ICA $(\mathrm{n}=8) ; 28$ patients referred for ICA did not require coronary intervention, and at the time of referral met ESC criteria for consideration of CTCA. ${ }^{4}$ The overall cost of these 28 referrals was £254 492 at $£ 9089$ per patient, and is itemised in table 4 .

\section{DISCUSSION}

The ESC currently recommends that CTCA should be considered as an alternative to ICA to exclude ACS when there is a low-intermediate risk of CHD, and when troponin and ECG are inconclusive. ${ }^{4}$ Our study supports these criteria in terms of statistical difference in patient variable means for respective mortality risk, elevated 
Table 2 Multivariate regression analysis

\begin{tabular}{|c|c|c|c|c|}
\hline \multirow[b]{2}{*}{ Patient variable } & \multicolumn{2}{|l|}{ Univariate model } & \multicolumn{2}{|l|}{ Multivariate model } \\
\hline & OR (95\% Cl) & p Value & OR (95\% Cl) & p Value \\
\hline Sex (male) & 3.49 (1.86 to 6.54$)$ & $<0.001$ & 2.83 (1.29 to 6.18$)$ & 0.009 \\
\hline \multicolumn{5}{|l|}{ Risk factors } \\
\hline 0 & 1.00 & 1.000 & 1.00 & 1.00 \\
\hline 1 & 3.91 (1.48 to 10.44$)$ & 0.006 & 5.17 (1.59 to 16.81$)$ & 0.006 \\
\hline 2 & $2.41(0.96$ to 6.12$)$ & 0.062 & 2.01 (0.66 to 6.14$)$ & 0.221 \\
\hline 3 & $2.40(0.85$ to 6.51$)$ & 0.086 & 1.96 (0.58 to 6.63$)$ & 0.281 \\
\hline$>4$ & 6.23 (1.40 to 27.64$)$ & 0.017 & 7.9 (1.23 to 50.54$)$ & 0.029 \\
\hline ST-depression & 10.81 (4.37 to 26.78 ) & $<0.001$ & 7.72 (2.88 to 20.66$)$ & $<0.001$ \\
\hline NSTEMI & $4.62(2.17$ to 9.86$)$ & $<0.001$ & $0.29(0.02$ to 4.36$)$ & 0.372 \\
\hline Raised troponin & 5.46 (2.58 to 11.56$)$ & $<0.001$ & $7.49(0.53$ to 106.11$)$ & 0.137 \\
\hline Raised creatinine & 2.09 (1.04 to 4.20$)$ & 0.037 & $1.27(0.54$ to 3.03$)$ & 0.583 \\
\hline Grace score & $1.02(1.01$ to 1.03$)$ & $<0.001$ & $1.02(0.99$ to 1.05$)$ & 0.272 \\
\hline Grace score-6 month mortality risk & 2.18 (1.48 to 3.23$)$ & $<0.001$ & $0.88(0.27$ to 2.86$)$ & 0.833 \\
\hline
\end{tabular}

troponin and ST-segment shift. Of these ESC criteria, however, only ST-segment depression at presentation was independently associated with coronary intervention at ICA.

Of the 198 patients referred for ICA, 32 (16\%) met ESC criteria for consideration of CTCA as an alternative investigation. Of these 32, $28(88 \%)$ were discharged from the tertiary centre with no coronary intervention. The overall cost of these 28 referrals was £254492 at $£ 9089$ per patient. This figure does not include downstream cost for those $(n=8)$ who required prolonged inpatient admission. Preassessment with CTCA may have prevented a significant number of these ICA referrals.
At a fractional cost of $£ 376$ per patient, this would be significantly cost-effective for the referring hospital. A more indepth cost-benefit evaluation is limited, given angiographic findings were not correlated in those who underwent CTCA prior to transfer.

Patients with suspected ACS usually go on to have a diagnostic ICA which is expensive and not without shortterm risk to the patient. ${ }^{18}$ The absolute benefit to the patient with ACS is smaller than many would expect with debated long-term survival benefits. ${ }^{19}$ In addition, in order to undertake ICA, the majority of patients require transportation between hospitals by land and occasionally by sea or air.

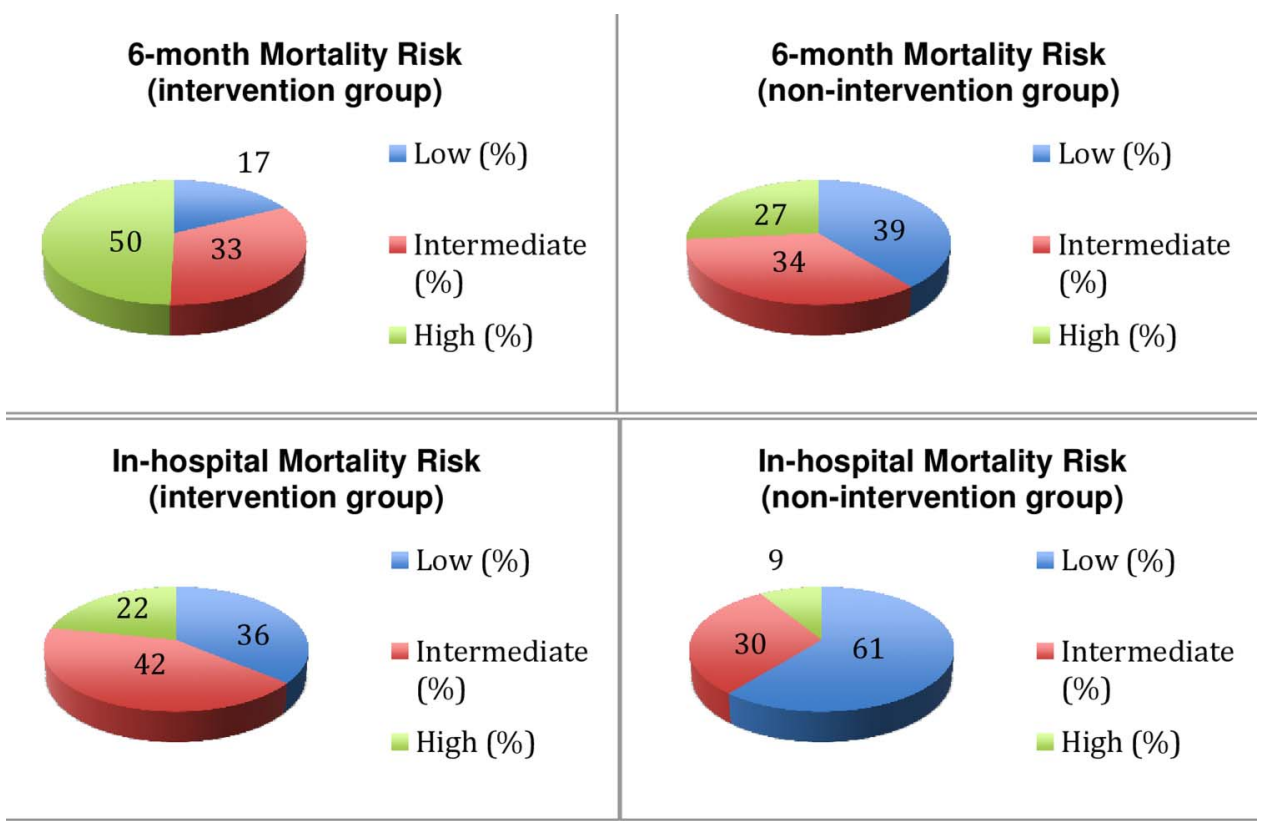

Figure 1 The GRACE risk stratification for both intervention and non-intervention groups. GRACE In-Hospital Mortality Risk scores: 1-108=low, 109-140=intermediate, 141-372=high. GRACE 6-month Mortality Risk scores: 1-88=low, 89118=intermediate, 119-263=high 146×103 mm. GRACE, Global registry of Acute Coronary Events. 
Table 3 Cost of care for those patients referred for invasive coronary angiography (ICA) not requiring coronary intervention

\begin{tabular}{|c|c|c|c|}
\hline Cost item & Cost/patient (£) & Number & Total (£) \\
\hline $\begin{array}{l}\text { Transport } \\
\text { (including return } \\
\text { to local } \\
\text { hospital) }\end{array}$ & 2512 & 79 & 198448 \\
\hline Transfer team & 400 & 79 & 31600 \\
\hline $\begin{array}{l}\text { Non-elective } \\
\text { diagnostic } \\
\text { conventional } \\
\text { angiogram }\end{array}$ & 3544 & 79 & 279976 \\
\hline $\begin{array}{l}\text { Bed on Acute } \\
\text { Medical Unit at } \\
\text { Jersey General } \\
\text { Hospital (1 day) }\end{array}$ & 366 & 317 & 116022 \\
\hline $\begin{array}{l}\text { Bed on } \\
\text { cardiology ward } \\
\text { at accepting } \\
\text { hospital ( } 1 \text { day) }\end{array}$ & 232 & 442 & 102544 \\
\hline Total cost & & & 728950 \\
\hline Cost/patient & & & 9227 \\
\hline
\end{tabular}

Ranasinghe et $a l^{20}$ evaluated the long-term mortality of 40482 patients with acute myocardial infarction admitted to hospitals in New South Wales; $25 \%$ of these patients underwent interhospital transfer for specialised care. They reported higher rates of coronary revascularisation and lower long-term mortality in those transferred for specialised care. They attributed the lower long-term mortality rates of this subgroup only partially to improved access of revascularisation facilities, but

Table 4 Cost of care for those patients referred for invasive coronary angiography (ICA) who did not require coronary intervention, and met European Society of Cardiology criteria ${ }^{4}$ for consideration of CTCA as an alternative investigation to ICA

\begin{tabular}{lccr}
\hline Cost item & $\begin{array}{l}\text { Cost/ } \\
\text { patient (£) }\end{array}$ & Number & Total (£) \\
\hline $\begin{array}{l}\text { Transport (including } \\
\text { return to local hospital) }\end{array}$ & 2512 & 28 & 70336 \\
$\begin{array}{l}\text { Transfer team } \\
\begin{array}{l}\text { Non-elective } \\
\text { diagnostic }\end{array}\end{array}$ & 400 & 28 & 11200 \\
$\begin{array}{l}\text { conventional } \\
\text { angiogram }\end{array}$ & 3544 & 28 & 99232 \\
$\begin{array}{l}\text { Bed on Acute Medical } \\
\text { Unit at Jersey General }\end{array}$ & 366 & 126 & 46116 \\
$\begin{array}{l}\text { Hospital (1 day) } \\
\text { Bed on cardiology }\end{array}$ & 232 & 119 & \\
$\begin{array}{l}\text { ward at accepting } \\
\text { hospital (1 day) }\end{array}$ & & & \\
$\begin{array}{l}\text { Total cost } \\
\text { Cost/patient }\end{array}$ & & & \\
\hline
\end{tabular}

rather, that of evidence-based beneficial therapies such as dual antiplatelet and antithrombotic agents, prognostically significant evaluations and specialised cardiology care. $^{20}$ Locally performed prognostic evaluation with CTCA could, therefore, be used to identify a subgroup of patients most appropriate for interhospital transfer and its associated benefits, as outlined by Ranasinghe et al.

Our study retrospectively identifies a target subgroup of patients that could safely have been investigated with CTCA prior to assessment for referral to a tertiary centre in the UK. A strength of the design used in this study is that the cohort evaluated reflects real everyday practice. Although a precise cost-benefit analysis of this clinical decision model could not be calculated, our data indicate that there are considerable cost savings if CTCA is used in selected patients with ACS. The emotional, practical and manpower costs of inpatient transfer are also reduced.

Four recent randomised control studies (CT-STAT, ACRIN-PA, ROMICAT II and CT-COMPARE) have compared US conventional current standards of care with the adoption of $\mathrm{CTCA}^{21-24}$ in patients presenting with non-ACS chest pain. All supported the safe discharge of low-intermediate risk patients with negative CTCA findings from the ED. All four trials also reported reduced length of inpatient stay at considerably lower cost.

Given the high sensitivity and specificity of CTCA for the detection of ACS, we believe that there is a group of patients who could be managed medically that could be identified prior to referral for ICA. The RAPID-CTA study (clinical trial reference NCT02284191) is starting to recruit patients in the UK to investigate the effect of early CTCA in patients with suspected or confirmed ACS on interventions, event rates and healthcare costs; results of which are eagerly awaited.

\section{Study limitations}

There are several limitations of this study that warrant further consideration. Although the majority of patients were in sinus rhythm $(90 \%)$, not tachycardic $(84 \%)$, and without kidney injury (82\%) at presentation, not all patient characteristics for CTCA suitability were assessed. We therefore cannot assume that all those patients retrospectively deemed 'suitable' for CTCA were, in fact, clinically so. Another limitation of the study is the generalisation of cost figures across UK hospitals. The impact of aeromedical transfer on cost figures is significant and must be carefully considered. Despite this, we believe onsite CTCA would be cost-effective for the majority of hospitals without onsite revascularisation facilities. Concern has been raised regarding the effective dose radiation (EDR) of CTCA. Iterative reconstruction of CT scanners has led to a significant improvement in scan duration, image quality and EDR. Tube modulation, ECG-gating and high pitch spiral acquisitions are methods used to further reduce the exposure of patients 
to radiation. ${ }^{25} 26 \mathrm{~A}$ combination of these acquisition techniques has resulted in radiation doses below $1 \mathrm{mSv}$ when using dual-source CTCA with high-pitch helical mode studies. ${ }^{25}{ }^{26}$ There is concern that using CTCA for the triage of patients with ACS may lead to increased rates of ICA, and thus, downstream costs. One meta-analysis concluded that the use of CTCA in lowintermediate risk patients with ACS is safe and reduces length of stay. There was, however, a small, but significant, $2 \%$ increase in rates of ICA and surgical revascularisation in the CTCA group compared with standard care. ${ }^{27}$ Downstream cost figures were also evaluated in a large multicentre registry (CONFIRM) with 155207 intermediate-risk patients. They reported low referral rates in patients without $\mathrm{CHD}$ and mild CHD at CTCA (2.5\% and $8.3 \%$, respectively).$^{28}$ CONFIRM investigators reported a low overall rate of ICA $(12.5 \%)$ suggesting that CTCA was operating as a filter with most ICA referrals limited to patients with obstructive CHD. Downstream cost is part determined by additional diagnostic work-up, which reflects real practice. The decision to refer for ICA is, however, a largely subjective decision and does not directly reflect CTCA findings.

\section{CONCLUSIONS}

Low-intermediate risk patients presenting with suspected or proven ACS to hospitals without onsite coronary revascularisation should be considered for in-hospital CTCA before referral for ICA. A decision model using CTCA as a gatekeeper for targeted ICA would result in reduced frequency and length of admissions, reduced cost, improved patient experience, and early initiation of preventative therapy. Consideration should be made to expand the use of CTCA to other patients groups presenting with suspected or proven ACS.

\section{Competing interests None declared.}

Ethics approval Local Jersey Health Ethics Committee.

Provenance and peer review Not commissioned; externally peer reviewed.

Data sharing statement No additional data are available.

Open Access This is an Open Access article distributed in accordance with the Creative Commons Attribution Non Commercial (CC BY-NC 4.0) license, which permits others to distribute, remix, adapt, build upon this work noncommercially, and license their derivative works on different terms, provided the original work is properly cited and the use is non-commercial. See: http:// creativecommons.org/licenses/by-nc/4.0/

\section{REFERENCES}

1. Goodacre S, Cross E, Lewis C, et al., on behalf of the ESCAPE Research Team. Effectiveness and safety of chest pain assessment to prevent emergency admissions. BMJ 2007;335:659-62.

2. National Institute for Health and Care Excellence. Chest pain of recent onset: assessment and diagnosis of recent onset chest pain or discomfort of suspected cardiac origin. NICE clinical guideline 95 [Internet]. London: NICE, 2012.

3. British Cardiology Interventional Society. Audit Returns: Adult Interventional Procedures. 2012. http://www.bcis.org.uk/resources/ BCIS Audit 2012 for web V2 14-10-20131.pdf

4. Roffi $\bar{M}$, Patrono $\mathrm{C}$, Collet JP, et al. 2015 ESC Guidelines for the management of acute coronary syndromes in patients presenting without persistent ST-segment elevation Task Force for the Management of Acute Coronary Syndromes in Patients Presenting without Persistent ST-Segment Elevation of the European Society of Cardiology (ESC). Eur Heart J 2016;37:267-315.

5. Montalescot G, Sechtem U, Achenbach S, et al. 2013 ESC guidelines on the management of stable coronary artery disease: the Task Force on the Management of Stable Coronary Artery Disease of the European Society of Cardiology. Eur Heart $J$ 2013;34:2949-3003.

6. Shah BN, Balaji G, Alhajiri A, et al. Incremental diagnostic and prognostic value of contemporary stress echocardiography in a chest pain unit: mortality and morbidity outcomes from a real-world setting. Circ Cardiovasc Imaging 2013;6:202-9.

7. Gaibazzi N, Reverberi C, Badano L. Usefulness of contrast stress-echocardiography or exercise-electrocardiography to predict long-term acute coronary syndromes in patients presenting with chest pain without electrocardiographic abnormalities or 12-hour troponin elevation. Am J Cardiol 2011;107:161-7.

8. Ingkanisorn WP, Kwong RY, Bohme NS, et al. Prognosis of negative adenosine stress magnetic resonance in patients presenting to an emergency department with chest pain. J Am Coll Cardiol 2006;47:1427-32.

9. Lim SH, Anantharaman V, Sundram F, et al. Stress myocardial perfusion imaging for the evaluation and triage of chest pain in the emergency department: a randomized controlled trial. J Nucl Cardiol 2013:20:1002-12.

10. Nabi F, Chang SM, Xu J, et al. Assessing risk in acute chest pain: the value of stress myocardial perfusion imaging in patients admitted through the emergency department. J Nucl Cardiol 2012;19:233-43.

11. Meijboom WB, van Mieghem CA, Mollet NR, et al. 64-Slice computed tomography coronary angiography in patients with high, intermediate, or low pre-test probability of significant coronary artery disease. J Am Coll Cardiol 2007;50:1469-75.

12. Min JK, Shaw LJ, Devereux RB, et al. Prognostic value of multidetector coronary computed tomographic angiography for prediction of all-cause mortality. J Am Coll Cardiol 2007;50:1161-70.

13. van Velzen JE, de Graaf FR, Kroft LJ, et al. Performance and efficacy of 320-row computed tomography coronary angiography in patients presenting with acute chest pain: results from a clinical registry. Int J Cardiovasc Imaging 2012;28:865-76.

14. Mowatt G, Cummins E, Waugh N, et al. Systematic review of the clinical effectiveness and cost-effectiveness of 64-slice or higher computed tomography angiography as an alternative to invasive coronary angiography in the investigation of coronary artery disease. Health Technol Assess 2008;12:iii-iv, ix-143.

15. Meijs MF, Meijboom WB, Prokop M, et al. Is there a role for CT coronary angiography in patients with symptomatic angina? Effect of coronary calcium score on identification of stenosis. Int $J$ Cardiovasc Imaging 2009;25:847-54.

16. Scheske JA, O'Brien JM, Earls JP, et al. Coronary artery imaging with single-source rapid kilovolt peak-switching dual-energy CT. Radiology 2013;268:702-9.

17. lyengar S, Gosling O, Raju V, et al. Diagnostic accuracy of high-definition computed tomographic angiography compared to invasive coronary angiography in the assessment of patients with high pre-test probability of or established coronary artery disease. Heart 2012;98:A58.

18. Thygesen K, Alpert JS, Jaffe AS, et al. Third universal definition of myocardial infarction. Eur Heart J 2012;33:2551-67.

19. Hoenig MR, Aroney CN, Scott IA. Early invasive versus conservative strategies for unstable angina and non-ST elevation myocardial infarction in the stent era. Cochrane Database Syst Rev 2010;(3): CD004815.

20. Ranasinghe I, Barzi F, Brieger D, et al. Long-term mortality following interhospital transfer for acute myocardial infarction. Heart 2015;101:1032-40.

21. Goldstein JA, Chinnaiyan KM, Abidov A, et al. The CT-STAT (Coronary Computed Tomographic Angiography for Systematic Triage of Acute Chest Pain Patients to Treatment) trial. J Am Coll Cardiol 2011;58:1414-22.

22. Litt HI, Gatsonis C, Snyder B, et al. CT angiography for safe discharge of patients with possible acute coronary syndromes. N Engl J Med 2012;366:1393-403.

23. Hoffmann U, Truong QA, Schoenfeld DA, et al. Coronary CT angiography versus standard evaluation in acute chest pain. $N$ Engl J Med 2012;367:299-308.

24. Hamilton-Craig C, Fifoot $A$, Hansen $M$, et al. Diagnostic performance and cost of $C T$ angiography versus stress ECG-a randomized prospective study of suspected acute coronary syndrome chest pain 
in the emergency department (CT-COMPARE). Int J Cardiol 2014;177:867-73.

25. Carrascosa P, Rodriguez-Granillo GA, Capunay C, et al. Low-dose CT coronary angiography using iterative reconstruction with 256-slice CT scanner. World $J$ Cardiol 2013;5:382-6.

26. Hausleiter J, Meyer T, Hadamitzky M, et al. Radiation dose estimates from cardiac multislice computed tomography in daily practice: impact of different scanning protocols on effective dose estimates. Circulation 2006;113:1305-10.
27. Hulten E, Pickett C, Bittencourt MS, et al. Outcomes after coronary computed tomography angiography in the emergency department: a systematic review and meta-analysis of randomized controlled studies. J Am Coll Cardiol 2013;61:880-92.

28. Shaw LJ, Hausleiter J, Achenbach S, et al. Coronary computed tomography angiography as a gatekeeper to invasive diagnostic and surgical procedures; results from the multicentre CONFIRM (Coronary CT Angiography Evaluation for Clinical Outcomes: an International Multicentre) registry. J Am Coll Cardiol 2012;60:2103-14. 